\title{
Use of aquatic mesocosms in ecotoxicology: State of the art and perspectives
}

\author{
Th. Caquet \\ Ecology and Zoology Laboratory, UPRESA 8079 du CNRS, Ecology, \\ Systematics and Evolution, bátiment 442, Université Paris-Sud, 91405 Orsay, France
}

\begin{abstract}
Aquatic mesocosms have been used in ecotoxicology for approximately 15 years. They provide a realistic approach for the evaluation of the effects of chemicals at many different levels of organization for different types of organisms. They offer the ability to predict changes at the highest levels of organization (population, community and ecosystem) from measurements of individual endpoints. In the context of hazard assessment, mesocosms can be used to refine estimates of the predicted concentrations in various compartments of ecosystems and of concentrations that will not cause any effect on living organisms. Ecotoxicological investigations in mesocosms will never entirely replace the use of laboratory animals. However, they allow the tests to be performed on species that are not of major 'societal' concern, but which play key-roles in the structure and functioning of ecosystems. In this respect, mesocosms allows non-destructive measurements of integrated endpoints. These systems can also be used to identify and quantify links anong changes measured at the individual level and their consequences at population and community levels. This paper reviews key features of mesocosms that can be critical for their use in environmental risk assessment of pollutants and emphasises on the optimisation of their use for such purpose.
\end{abstract}

\section{INTRODUCTION}

Model ecosystems may provide valuable information for the assessment of the fate and effects of chemicals. In particular, they give the opportunity to simultaneously identify direct and indirect effects of toxicants and to investigate responses at different levels of biological organization in fairly controlled conditions of exposure. Processes that reduce, such as adsorption on suspended solids or sediments, or enhance, such as bioturbation or bioaccumulation, the bioavailability of contaminants can also be taken into account using these devices. This paper reviews key features of mesocosm that can be critical for their use in environmental risk assessment of pollutants and emphasises on the optimisation of their use for such purpose.

\section{DEFINITION AND MAIN FEATURES}

According to the classical definition of Odum [1] and its further refinement by various authors [2, 3] mesocosms are artificial ecosystems, which are spatially bounded and located under natural environmental conditions. The term mesocosm is currently used to describe indoor and outdoor artificial streams or experimental ponds and enclosures (Figure 1). Basic features of these experimental devices have been thoroughly reviewed [3,4]. Mesocosms are systems, which ensure [4]:

- A self-sustainable functioning for the duration of the experiment,

- The identification of direct (and eventually indirect) effects of tested compounds,

- The co-occurrence of several trophic levels/functional-feeding groups, with organisms, which are representative of the regional flora and fauna,

- The feasibility of experimental manipulations (c.g. control of contamination level),

- Measurements and sampling without significant effects on their structure or dynamics (e.g. use of adapted sampling systems, caging of organisms, ...).

The originality of mesocosms is mainly based on the combination of ecological realism, achieved by introduction of the basic components of natural ecosystems, and facilitated access to a number of physico-chemical, biological and toxicological parameters that, to some extent, can be controlled. Chemical testing in such systems is more realistic than laboratory tests and easier than field assessment of chemical effects $[1,5-7]$. Furthermore, they allow the tests to be performed on species that are not of

- Present address: UMR INRA Ecobiology and Quality of Continental Hydrosystems, 65 nue de Saint-Brieuc,

35042 Rennes cedex, France. 
major 'societal' concern, but which play key-roles in the structure and functioning of ecosystems. They also give the opportunity to make measurements of various biological variables such as biomarkers and to identify links between such parameters and more integrated endpoints [4].



Figure 1: Place of mesocosms among the various experimental contexts used in aquatic ecotoxicology ([4]).

From laboratory tests to field studies, complexity and ecological representatives increase whereas replicability decreases. Laboratory tests provide information on the acute or chronic toxicity of tested compounds for isolated species. Simplified food chains may be used to study the transfer of contaminants through food and identify bioamplification phenomena. Laboratory microcosms may give the opportunity to simultaneously expose several species and to characterize the fate of compounds under more realistic conditions than in classical laboratory studies (e.g. presence of sediments). The results of laboratory study may be used to elaborate mode's (e.g. fate models), which may be validated under other experimental conditions. Outdoor studies give the opportunity to simultaneously assess the fate and effects of tested compounds and to evaluate their effects at various levels of biological organization. Under natural environmental conditions, various experimental tools may be used such as artificial streams, experimental ponds and enclosures. Among enclosures, a distinction can be made between limnocorrals, pelagic bags and littoral enclosures. Limnocorrals are placed in the pelagic region of ponds, lakes, or marine environments and they are in contact with the sediments whereas pelagic bags only enclose the water column. Littoral enclosures are built using dividers that isolate the littoral region of lentic ecosystems. Despite its high ecological representatives, the contamination of previously undisturbed natural ecosystems raises many ethical problems. Results of the experiments performed under field conditions may be used to validate and/or improve models.

\section{STRATEGY OF MESOCOSM DESIGN AND USE}

Realism, representatives and replicability of mesocosms are critical for evaluating their usefulness in risk assessment procedures. Ecological realism may be achieved by introduction of the basic components of natural ecosystems. These systems offer a facilitated access to a number of physico-chemical, biological and toxicological parameters that, to some extent, can be controlled. This determines various features of the systems such as the minimal size required; initial physico-chemical and biological composition or choice of model species for ecotoxicological investigations [4]. Although size has frequently been 
identified as a criteria to distinguish between microcosms and mesocosms, many experts now consider that the most important point is to ensure long-term self-functioning of the ecosystem and the word 'cosm' is frequently used to describe these experimental systems.

Considering the objectives of most studies carried out in mesocosms, replicability is the most important point. It may be achieved, in part, by a relative simplification of the systems. Reconstituted systems do not need to exactly simulate natural conditions at all levels but key features at both structural and functional levels should be preserved as they insure ecological representatives. One of the objectives of current practices performed in mesocosms is to make simplifications on bounded ecosystems in order to reduce unexplained variability or to isolate mechanisms without invalidating the conclusions or predictions that can be made. Since each natural ecosystem is unique as its structure and function mainly depend on local factors, it is not possible to define a 'standard' mesocosm.

The choice of the experimental design should be based on the objectives of the study rather than on theoretical considerations. The most frequently used experimental design includes both a no-effect concentration and a very effective one, with at least one intermediate effect concentration. Control and treated mesocosms should be replicated. Whatever the experimental design, the intrinsic variability of the endpoints should be assessed prior or during the measurement period [8]. Identification of contaminant effects will generally be more difficult and will necessitate more replicates for highly variable endpoints than for less variable endpoints. Usually a threshold level of 1 to $5 \%$ for rejection of null hypothesis (Type I error; i.e. the risk to reject the hypothesis that treatment has no effect while it is true) is used. However the main point in environmental risk assessment should be to ensure that Type II error (i.e. the risk to accept the null hypothesis while it is false) is minimal. Minimization of Type II error for threshold levels of 1 to $5 \%$ may theoretically be obtained by increasing the number of replicates. However, this may be incompatible with the available human and financial resources and with the variability of measured endpoints [8]. Therefore, higher threshold levels (15-20\%) have been proposed in the case of whole-system ecotoxicological experiments [9-11].

\section{PAST AND CURRENT USE OF MESOCOSMS FOR THE ENVIRONMENTAL RISK ASSESSMENT OF CHEMICALS}

Environmental risk assessment is a multi-tiered approach, which is mainly based on the comparison between predicted environmental concentrations (PECs) and estimates of concentrations that will not cause any effect on living organisms (NOECs: No Observed Effect Concentrations; Figure 3; [6, 12-14]).

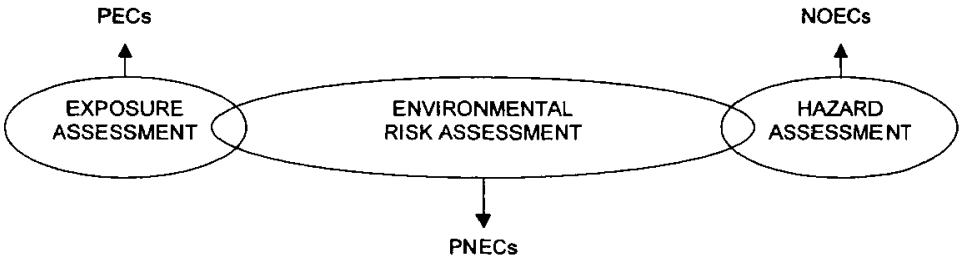

Figure 2. General principles of environmental risk assessment of chemicals (NOECs: No Observed Effect Concentrations; PECs: predicted environmental concentrations; PNECs: predicted no-effect environmental concentrations

Mesocosms give the opportunity to refine estimates of NOECs (e.g. through the simultaneous exposure of many species belonging to various taxa) and PECs (e.g. through fate studies) [15-17]. They may also be used to identify direct and indirect effects and to demonstrate (or not) recovery of contaminated systems (Figure 3 ).

Several guidance documents on mesocosm use for environmental risk assessment of chemicals have been elaborated [18-20] and new guidelines are currently under evaluation [21-22]. Within the second 
half of the 1980s large-scale mesocosms were compulsory for the registration of new pesticides (e.g. pyrethroids) in the United States, but at the beginning of the 1990s tests using these systems were abandoned because of because their cost-effectiveness was questionable [23]. According to the current U.S. regulation, potential adverse ecological effects of pesticides are collected following a tiered approach. Mesocosm studies are the final tier of this approach [24,25], but such studies are not compulsory [25]. In the European Union, the EU directive 91/414 for the environmental risk characterization of pesticides, which is also based on a tiered approach, indicates that mesocosm studies may be required by experts [26].

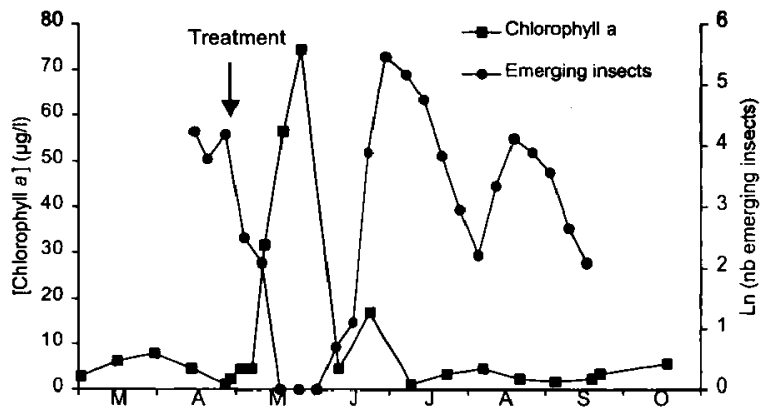

Figure 3. Example of indirect effect of a pesticide (pyrethroid insecticide deltamethrin) identified during a freshwater mesocosm study ([27]).

Deltamethrin caused a sharp decrease in the abundance of arthropods (zooplanktonic crustaceans, insects) as shown by the reduction of the abundance of emerging insects. Disappearance of herbivorous organisms was followed by a phytoplanktonic bloom (phytoplankton biomass was measured as $\mu \mathrm{g}$ chlorophyll a/l). The rapid disappearance of deltamethrin (half life time in water $<2 \mathrm{~h}$ ) facilitated the rapid recovery of insect community.

\section{CONCLUSION - CURRENT TRENDS FOR THE USE OF MESOCOSMS IN ENVIRONMENTAL RISK ASSESSMENT}

Regulatory procedures for higher-tier risk assessment are still under development and harmonization of the approaches used to characterize risks in the EU and the OECD promotes USA. Groups of experts are currently working on guidance documents for such higher-tier aquatic risk characterization [26, 28]. Among the various aspects which are discussed, emphasis is made on the use of more 'visual' statistical methods such as Redundancy Analysis (RDA) and Principal Response Curves (PRC) to facilitate expert judgment and communication of results [29]. In these meetings, study of recovery of contaminated systems has been pointed out as a major concem in mesocosm studies. However, this concept should be refined since it has many different definitions.

Increased interaction of ecotoxicology with fundamental ecology may significantly improve the use of experimental ecosystems through a better understanding of ecosystem functioning. Furthermore, new descriptors such as size-structure of communities, food web structure and functioning or ecosystem-level descriptors (resistance to introduction of new species, restoration dynamics / resilience, relationship between diversity and ecological function) may be used to evaluate the effects of contaminants. Conversely, experimental ecotoxicology may give the opportunity to obtain data on various phenomena such as the relationship between diversity and responses to perturbations or functional redundancy or the role of perturbations in structuring processes and ecosystem functioning. It may also provide data for the construction of quantitative and/or qualitative models of ecosystem functioning. 


\section{References}

[1] Odum E.P., BioScience 34 (1984) 558-562.

[2] Lalli C.M., Enclosed Experimental Marine Ecosystems: A Review and Recommendations (SpringerVerlag, New York, 1990).

[3] Grancy R.L., Giesy J.P. Jr, and Clark J.R., in Fundamentals of Aquatic Toxicology, G.M. Rand Ed., 2nd ed. (Taylor and Francis, Washington D.C., 1995) pp. 257-305.

[4] Caquet Th., Lagadic L. and Sheffield S.R., Rev. Environ. Contam. Toxicol. 165 (2000) 1-38.

[5] Caims J. Jr, Regul. Toxicol. Pharmacol. 8 (1988) 226-238.

[6] Crossland N.O., Toxicol. Ecotoxicol. News 1 (1994) 15-22.

[7] La Point T.W., in Freshwater Field Tests for Hazard Assessment of Chemicals, I.R. Hill, F. Heimbach, P. Leeuwangh and P. Matthiessen Eds. (Lewis Publishers, Boca Raton, 1994) pp. 83-94.

[8] Caquet Th., Lagadic L., Monod G., Lacaze J.-C. and Couté A., Ecotoxicology 10 (200I) 51-66.

[9] Christman V.D., Voshel] J.R. Jr., Jenkins D.G., Rosenzweig M.S., Layton R.J. and Buikema A.L. Jr, in Aquatic Mesocosm Studies in Ecological Risk Assessment, edited by R.L. Graney, J.H. Kennedy and J.H. Rodgers Jr. (Lewis Publishers, Boca Raton, 1994) pp. 105-127.

[10] Shaw J.L., Moore M., Kennedy J.H. and Hill I.R., in Aquatic Mesocosm Studies in Ecological Risk Assessment, Graney R.L., Kennedy J.H. and Rodgers J.H. Jr. Eds. (Lewis Publishers, Boca Raton, 1994) pp. 85-103.

[11] Stunkard C.L., in Aquatic Mesocosm Studies in Ecological Risk Assessment, R.L. Graney, J.H. Kennedy and J.H. Rodgers Jr. Eds. (Lewis Publishers, Boca Raton, 1994) pp. 71-83.

[12] Matthiessen P., in Freshwater Field Tests for Hazard Assessment of Chemicals, I.R. Hill, F. Heimbach, P. Leeuwangh and P. Matthiessen Eds. (Lewis Publishers, Boca Raton, 1994) pp. 455-473.

[13] van Leeuwen K., Emans H.-J., Van de Plassche E. and Canton H., in Freshwater Field Tests for Hazard Assessment of Chemicals, I.R. Hill, F. Heimbach, P. Leeuwangh and P. Matthiessen Eds. (Lewis Publishers, Boca Raton, 1994) pp. 425-437.

[14] Suter G.W. II, in Fundamentals of Aquatic Toxicology, G.M. Rand Ed., 2nd ed. (Taylor and Francis, Washington D.C., 1995).

[15] Crossland N.O., Mitchell G.C. and Dorn P.B., Environ. Toxicol. Chem. 11 (1992), 49-59.

[16] Fairchild J.F., Dwyer F.J., La Point T.W., Burch S.A. and Ingersoll C.W., Environ. Toxicol. Chem. 10 (1993) 1763-1776.

[17] Taylor E.J., Maund S.J., Bennett D. and Pascoe D., Ecotoxicol. Environ. Safety 29 (1994) 80-85.

[18] Touart L.W., Aquatic Mesocosm Test to Support Pesticide Registrations. Hazard Evaluation Division Technical Guidance Document. (U.S. E.P.A., Washington D.C, 1988).

[19] SETAC-RESOLVE, Guidance Document on Testing Procedures for Pesticides in Freshwater Static Mesocosms (SETAC, Pensacola, 1992).

[20] SETAC-Europe, Guidance Document on Testing Procedures for Pesticides in Freshwater Mesocosms (SETAC-Europe, Brussels, 1992).

[21] OECD, Guidelines for Testing of Chemicals. Draft Proposal for a Guidance Document. Freshwater Lentic Field Tests (OECD, Paris, 1996).

[22] US EPA OPPTS, Ecological Effects Test Guidelines, OPPTS 850.1950, Field Testing for Aquatic Organisms (U.S. E.P.A., Washington D.C, 1996).

[23] Boyle T.P. and Fairchild J.F., Ecol. Applic. 7 (1997) 1099-1102.

[24] Nabholz J.V., Clements R.G. and Zeeman M.G., Ecol. Applic. 7 (1997) 1094-1098.

[25] Touart L.W. and Maciorowski A.F., Ecol. Applic. 7 (1997) 1086-1093.

[26] Campbell P.J., Arnold D., Brock T., Grandy N., Heger W., Heimbach F., Maund S.J. and Streloke M. Eds., Higher-tier Aquatic Risk Assessment for Pesticides (SETAC-Europe Publications, Brussels, 1999).

[27] Caquet Th., Thybaud E., Le Bras S., Jonot O. and Ramade F., Aquat. Toxicol. 23 (1992) 261-278.

[28] Community Level Aquatic System Studies Interpretation Criteria - CLASSIC, in preparation.

[29] van den Brink P.J. and Ter Braak C.F., Environ. Toxicol. Chem. 18 (1999) 138-157. 